\title{
BUDAYA ORGANISASI DAN AKTIVITAS DAKWAH
}

\author{
Ahmad Yasser Mansyur dan Ahmad \\ Pusat Studi Psikologi Islami (PSPI) \\ Fakultas Psikologi Universitas Negeri Makassar \\ Email: ahmadyasser_mansyur@yahoo.com
}

\begin{abstract}
This study aimed to examine the influence of Muhammadiyah organization's culture against cultural dakwah activities carried out by the teachers. Demographic aspects included to be tested to determine the difference in the variables studied. This was a population research, the subject of research were the teachers with Muballigh status at the Twigs and Branches levels of Muhammadiyah Tello Baru Makassar amounted of 44 peoples. Two measuring devices used to collect information about the variables studied, the scale of the organization's culture and dakwah. Technique used to analyze the data were simple regression and $\mathrm{T}$ test. The results showed that the organization's culture affected the cultural propaganda significantly $(\mathrm{F}(1,42)=$ $39.189, \mathrm{p}<.05)$, with 48.3 percent of variants donations. From demography aspect, based on sex, showed no differences in organization's culture and dakwah.
\end{abstract}

Key words: organization's culture and cultural dakwah

\begin{abstract}
Abstrak
Kajian ini bertujuan untuk menguji pengaruh budaya organisasi Muhammadiyah terhadap aktivitas dakwah kultural yang dilakukan oleh para guru. Aspek demografi turut diuji untuk mengetahui perbedaannya dalam variabel yang dikaji. Penelitian ini merupakan penelitian populasi, dimana subjek penelitian adalah guru berstatus Muballigh di Tingkat Ranting dan Cabang Muhammadiyah Tello Baru Kota Makassar yang berjumlah 44 orang. Dua alat ukur digunakan untuk mengumpulkan informasi mengenai variabel yang diteliti, yaitu skala budaya organisasi dan dakwah. Digunakan teknik analisis regresi sederhana dan uji T untuk menganalisis data yang ada. Hasil kajian menunjukkan budaya organisasi mempengaruhi dakwah kultural secara signifikan $(F(1,42)=39.189, p<.05)$, dengan 48,3 persen sumbangan varian. Dari aspek demografi, menunjukkan tidak terdapat perbedaan budaya organisasi dan dakwah kultural berdasar jenis kelamin.
\end{abstract}

Kata-kata kunci: budaya organisasi, dakwah kultural

B erawal dari Firman Allah SWT. dalam alQur`an surat An-Nahl: 125 berikut:

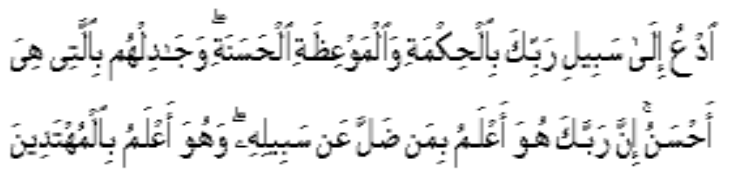

"Serulah (manusia) kepada jalan Tuhanmu dengan hikmah dan pelajaran yang baik dan bantahlah mereka dengan cara yang baik. Sesungguhnya Tuhanmu Dialah yang lebih mengetahui tentang siapa yang tersesat dari jalan-Nya dan Dialah yang lebih mengetahui orang-orang yang mendapat petunjuk".

Al-Qur`an merupakan kitab suci, petunjuk bagi manusia (hudan linnas) yang memuat konsep-konsep sistemik dan referensi kebenaran ilmu pengetahuan yang dapat diaplikasikan dalam setiap dimensi kehidupan. Begitu pula bagi ummat islam, al-Qur’an senantiasa menjadi sumber nilai pertama dan utama dalam kehidupan individu, masyarakat, 
organisasi bahkan kehidupan berbangsa sekalipun. Inilah yang perlu disampaikan ke ummat manusia melalui dakwah dan seruan untuk kembali ke pedoman hidup utama tersebut.

Secara etimologis, dakwah berasal dari bahasa Arab: da`aa - yad'uu - da`watan, yang berarti ajakan, seruan atau himbauan, (Sholeh, $200 \&$ Munawir, 20025 ). Secara terminologis, pengertian dakwah dapat diuraikan dari beberapa pendapat berikut:

1) Pengertian dakwah dalam al-Qur`an terdapat dalam Surat Ali Imran/, ayat 104 dan 110

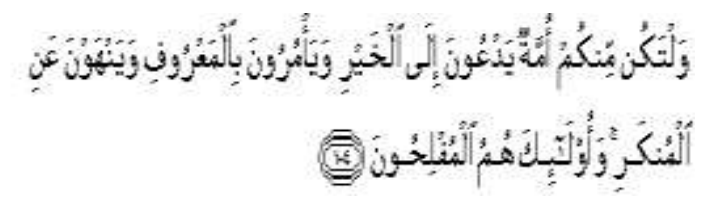

Dan hendaklah ada di antara kamu segolongan umat yang menyeru kepada kebajikan, menyuruh kepada yang ma'ruf dan mencegah dari yang munkar, merekalah orang-orang yang beruntung. (QS. Ali Imran, ayat 104)

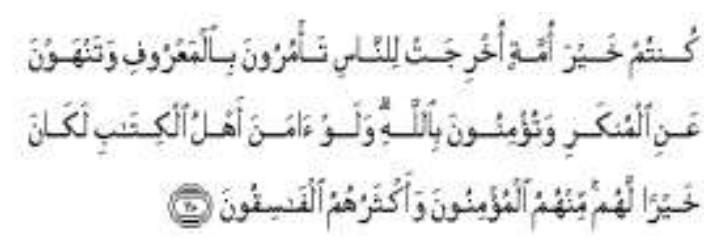

"Kamu adalah umat yang terbaik yang dilahirkan untuk manusia, menyuruh kepada yang ma'ruf, dan mencegah dari yang munkar, dan beriman kepada Allah. Sekiranya Ahli Kitab beriman, tentulah itu lebih baik bagi mereka, di antara mereka ada yang beriman, dan kebanyakan mereka adalah orang-orang yang fasik". (QS. Ali Imran, ayat 110).

2) Menurut Pimpinan Pusat Muhammadiyah (2003) dakwah sebagai wujud menyeru dan membawa umat manusia ke jalan Allah. Sebagaimana terdapat dalam Q.S. Yusuf/112: 108.

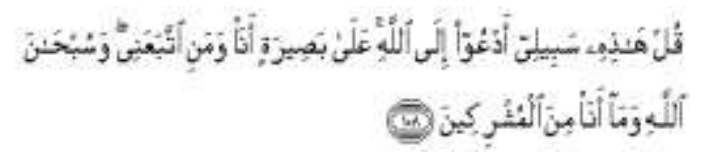

"Katakanlah: Inilah jalan (agama) ku, aku dan orang-orang yang mengikutiku mengajak (kamu) kepada Allah dengan hujjah yang nyata, Maha Suci Allah, dan aku tiada termasuk orang-orang yang musyrik."

Upaya mewujudkan Islam dalam kehidupan dilakukan melalui da'wah itu ialah mengajak kepada kebaikan (amar ma'ruf), mencegah kemungkaran (nahyu munkar), dan mengajak untuk beriman (tu'minuna billah) guna terwujudnya umat yang sebaik-baiknya atau khairu ummah.

Dari beberapa pendapat di atas, maka dapat disimpulkan bahwa dakwah adalah rangkain ikhtiar secara sadar yang dilakukan orang atau kelompok (organisasi) untuk mengajak orang atau umat manusia ke jalan Allah SWT dan menuju kehidupan islami. Sebagaimana telah diketahui, bahwa inti dari aktivitas dakwah adalah mengajak. Dalam Psikologi, aktivitas mengajak terdapat dalam konsep psikologi sosial, yaitu konsep social influence (pengaruh sosial) dan persuasion (persuasi). Konsep pengaruh sosial digunakan dalam interaksi antar personal dalam kehidupan sosial. Untuk mempengaruhi dan mengubah sikap orang lain digunakan konsep persuasi. Persuasi merupakan metode dan bagian terdalam dari proses pengaruh sosial.

Konsep pengaruh sosial sebagaimana dikutip dari Baron dan Byrne (1981) adalah tindakan yang dilakukan oleh seseorang atau sekumpulan orang untuk mengubah sikap, tingkah laku atau perasaan orang lain. Pengaruh sosial merupakan perubahan dalam tingkah laku, niat, kepercayaan, dan atau nilai seseorang akibat dari campur tangan orang lain. (Tedeschi et al., 1995).

Menurut kamus Wikipedia (2007) persuasi adalah :

Persuasion is an active method of influence that attempts to guide people toward the adoption of an attitude, idea, or behavior by rational or emotive means. Persuasion relies on "appeals" rather than strong pressure or coercion. Numerous variables have been found to influence the persuasion process, and these are normally presented in four 
major categories: who said what to whom and how.

Menurut pengertian di atas, persuasi merupakan suatu metode pengaruh yang secara aktif mengarahkan seseorang orang-orang menuju perubahan sikap, gagasan, atau perilaku. Persuasi berdasarkan pada "pendekatan", bukan bersifat paksaan.

Sedangkan Newcomb et al. (1978) memberikan batasan, bahwa persuasi adalah suatu keadaan khusus dari pengaruh interpersonal, dimana salah satu pihak mengajukan satu titik pandangan kepada pihak lain. Agar persuasi dapat berlangsung dengan baik, maka dibutuhkan komponen persuasi. Menurut Sears et al. (1992) bahwa dalam persuasi harus ada empat komponen, sehingga persuasi dapat terlaksana dan dapat merubah perilaku seseorang, yaitu:

1) Pengirim atau komunikator (sender) adalah pihak yang mengurimkan pesan kepada pihak lain.Target. Penerima atau komunikate (receiver) adalah pihak yang menerima pesan dari pihak lain

2) Pesan (message) adalah isi atau maksud yang akan disampaikan oleh satu pihak kepada pihak lain.

3) Umpan balik (feedback) adalah tanggapan dari penerimaan pesan atas isi pesan yang disampaikannya.

Sebagai organisasi Islam, Muhammadiyah (bersama oganisasi otonom di bawahnya seperti: Anggota Muhammadiyah dan Aisyiyah, Nasyiatul Anggota Muhammadiyah dan Aisyiyah, Pemuda Muhammadiyah, Ikatan Mahasiswa Muhammadiyah, Ikatan Remaja Muhammadiyah, Hizbul Wathan, Tapak Suci,dll) telah mengikrarkan dirinya sebagai gerakan yang mengemban misi da'wah dan tajdid, berasas Islam, bersumber pada Al-Quran dan As-Sunnah (Nasir: 2007, PP Muhammadiyah: 2005). Muhammadiyah yang didirikan pada tahun 1912 oleh KH. Ahmad Dahlan di Yogyakarta. Dalam mengawali langkahnya, KH. Ahmad Dahlan menerjemahkan al-Qur`an surat Al-Maun ayat 1 - 7 dan surat Ali-
Imran ayat 104 yang memuat pesan implementasi nilai-nilai Al-qur`an dalam kehidupan soisal yang dilakukan secara teroganisir. Menurut Nasir (2007) bahwa sungguh tepat dan sangat mendasar jika Muhammadiyah sejak awal menisbahkan etos atau ruh gerakannya pada semangat alQur`an.

Dalam hubungannya dengan budaya organisasi, semangat "kembali kepada al-Qur'an dan Hadist" terutama terdapat pada surat Al-Maun ayat $1-7$ dan surat Ali-Imran ayat 104 telah menjadi nilai permanen dan ciri khas yang dimiliki oleh seluruh anggota organisasi Muhammadiyah. Bahkan kedua surat/ayat tersebut menurut Nasir (2007) menjadi "ayatnya orang Muhamamadiyah". Dari hal tersebut dapat diambil satu benang merah tentang adanya budaya organisasi yang mengakar dalam tubuh setiap anggota Muhamamdiyah hingga saat ini. Adanya budaya organisasi terebut dapat dilihat dari gerakan dakwah dan banyaknya amal usaha Muhammadiyah yang tersebar di seluruh Indonesia.

Berdasarkan pernyataan pikiran jelang satu abad Muhammadiyah yang disampaikan dalam Muktamar Muhamamdiyah ke 45 di Malang tahun 2005 (PP Muhammadiyah, 2005), dapat dirangkum beberapa hal yang penting yaitu:

1. Bahwa keberhasilan perjuangan Muhammadiyah yang berjalan hampir satu abad (100 tahun) pada hakikatnya merupakan rahmat dan karunia Allah Subhanahu wa Ta'ala yang patut disyukuri oleh seluruh warga Persyarikatan.

2. Dengan modal keikhlasan dan kerja keras segenap anggota disertai dukungan masyarakat luas Muhammadiyah tidak kenal lelah melaksanakan misi da'wah dan tajdid dalam memajukan kehidupan umat, bangsa, dan dunia kemanusiaan. Gerakan kemajuan tersebut ditunjukkan dalam melakukan pembaruan pemahaman Islam, pendidikan, kesehatan, kesejahteraan sosial, serta berperan dalam perjuangan kemerdekaan dan pembangunan bangsa di negeri ini.

3. Namun disadari pula masih terdapat 
sejumlah masalah atau tantangan yang harus dihadapi dan memerlukan langkahlangkah strategis dalam usianya yang cukup tua itu. Perjuangan Muhammadiyah yang diwarnai dinamika pasang-surut itu tidak lain untuk mencapai tujuan terwujudnya masyarakat Islam yang sebenar-benarnya serta dalam rangka menyebarkan misi kerisalahan Islam sebagai rahmatan lil-'alamin di bumi Allah yang terhampar luas ini.

Dari ayat dalam Al-qur'an dan pernyataan pikiran Muhammadiyah tersebut, tergambar jelas adanya nilai keikhlasan, kerja keras dan semangat berdakwah yang dimiliki seluruh anggota dalam mencapai tujuan organisasi Muhammadiyah. Nilai-nilai yang terakumulasi dalam kehidupan organisasi ini disebut oleh Sholeh (2005) sebagai budaya organisasi.

Pengertian budaya organisasi dalam perspektif psikologi disaimpaikan oleh Robbins (2005), yaitu budaya organisasi merupakan sistem pemaknaan bersama dibentuk oleh para warganya yang sekaligus menjadi pembeda dengan organisasi lain. Sistem pemaknaan bersama merupakan seperangkat karakter kunci dari nilainilai organisasi. Sedangkan dalam redaksi inggris, beberapa pengertian budaya organisasi diungkap berikut:

1) Organizational culture is the informal set of values and norms that controls the way people and groups in an organization interect with each other and with people outside the organization (George dan Jones 1996; 473).

2) Organisational culture is the shared system of beliefs and values, asevident in rituals, stories, myths and often a specialised language, that fosters a feeling of belonging (Langdon dan Marshall 1998; 193).

3) Organisational culture is the shared values, beliefs, norms, expectations, and assumptions that bind people an systems ( Weiss 2001; 348).

Berdasarkan pengertian di atas, maka dapat disimpulkan bahwa budaya organisasi adalah sistem norma dan nilai-nilai bersama bersifat informal (pedoman tidak tertulis) yang mengikat anggota organisasi. Nilai-nilai tersebut menjadi landasan gerak organisasi.

Perjalanan hidup Muhamamdiyah yang amat panjang itu tidak dapat dipungkiri tentunya telah melahirkan apa yang disebut budaya organisasi. Menurut Sholeh (2005), banyak nilai dan norma yang tumbuh, hidup dan berkembang dalam berMuhammmadiyah, nilai dan norma tentunya bersumber dari ajaran Islam, yang akhirnya menjadi budaya organisasi. Namun, dalam perjalannya yang kini menjelang satu abad, Muhammadiyah

mengalami gejala-gejala kelemahan ruh gerakan di sebagian kalangan warga Muhammadiyah.

Menurut Nasir (2007) dan Sholeh (2005) gejala penurunan semangat berMuhammadiyah, terutama dalam mengembangkan kegiatan-kegiatan yang jauh dari publikasi, kering dari kompensisikonpensasi fasilitas dan lain-lain. Hal itu dibuktikan dari adanya program dakwah kultural yang kurang mendapat sambutan dari warga, pimpinan dan Ortom Muhammadiyah. Permasalahan ini pula menimpa anggota Muhammadiyah dan Aisyiyah.

Berdasarkan pengenalan di atas, maka peneliti tertarik melakukan kajian kuantitatif untuk mengetahui seberapa besar budaya organisasi yang dimiliki oleh warga Muhammadiyah, khususnya yang berpropesi guru dalam melakukan program dakwah kultural di tengah dinamika kebudayaan dan perubahan sosial saat ini. Untuk mengetahui pengaruh budaya organisasi Muhammadiyah terhadap program dakwah kultural oleh para Guru Muhammadiyah.

\section{METODE}

Dinamika budaya organisasi Muhammadiyah dengan program dakwah perlu dikaji dan diketahui seberapa jauh pengaruhnya melalui pendekatan kuantitatif. Kajian secara kuantitaif ini akan meneliti dua variabel yaitu budaya organisasi dan program dakwah. Dalam kajian ini pula akan diteliti perbedaan demograpi 
daripada subyek/responden. Adapun kedua variabel itu dapat dilihat pada gambar 1 .

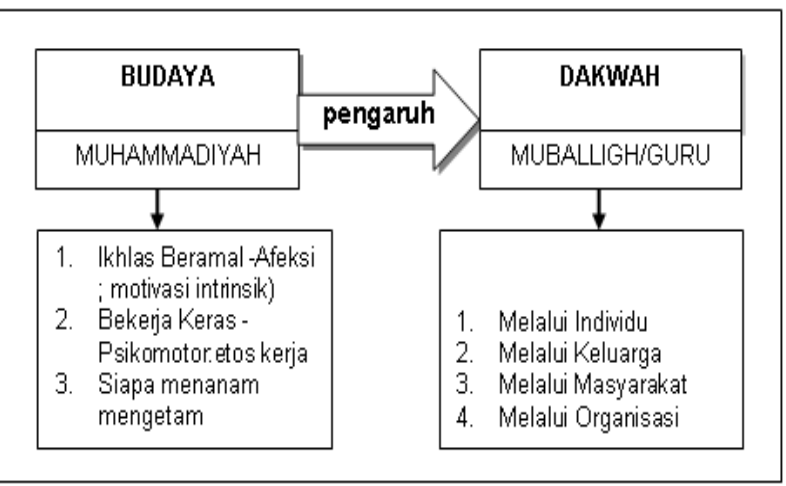

Subjek penelitian merupakan guru berstatus Muballigh (dai) di Tingkat Ranting dan Cabang Muhammadiyah Tello Baru Kota Makassar yang berjumlah 44 orang (diambil dari sampel porposif). Adapun aspek demografi subjek penelitian dapat dilihat pada tabel 1 .

Tabel 1 Subjek penelitian dalam demografi $(\mathrm{N}=44)$

\begin{tabular}{llc}
\hline Demografi & Spesifikasi & $\begin{array}{c}\text { Jumlah } \\
\text { Subjek }\end{array}$ \\
\hline Jenis kelamin & Laki-laki & 10 \\
& Perempuan & 34 \\
Pendidikan & SMA & 6 \\
& Diploma & 8 \\
& S1 & 28 \\
& S2 & 2 \\
Status & Menikah & 30 \\
pernikahan & & \\
& Belum & 14 \\
& menikah & \\
\hline
\end{tabular}

Sebelum dilakukan penelitian, terlebihdahulu dilakuakn uji validitas dan reliabilitas terhadap skala yang digunakan. Validitas berarti sejauhmana ketepatan dan kecermatan suatu alat ukur dalam melakukan fungsi ukurnya (Azwar 2003). Proses validitas dilakukan dengan dua tahap. Pertama, menghitung korelasi skor item (X) dengan skor komposit (Y). Kedua, menghitung korelasi bagian jumlah (part-whole correlation), dengan uji signifikan $\mathrm{p} \geq 0,05$. Reliabilitas alat ukur menunjukkan sejauh mana hasil pengukuran dengan alat tersebut dapat dipercaya. Ini ditunjukkan oleh taraf reliabilitas skor yang diperoleh oleh para subjek yang diukur dengan alat yang sama, atau diukur dengan alat yang setara pada kondisi yang berbeda (Azwar 2009).

Penilaian validitas item dalam penelitian ini menggunakan metode korelasi produk momen (moment product correlation, pearson correlation) dengan ketentuan validitas item lebih besar dari $\mathrm{r}$ kritis $=0,30$ pada corected item-total correlation (Sujianto, 2007). Namun menurut Azwar (2003), jika jumlah item belum cukup, maka bisa menurunkan batas kriteria 0.30 menjadi 0.25 . Uji reliabilitas alat ukur dilakukan dengan menggunakan metode Alpha Cronbach. Nilai koofesien alpha yang ditetapkan ialah di atas 0.60 (Sujianto 2007). Menurut Sujianto terdapat lima tingkatan alpha, iaitu: $0.00-0.20$ $=$ kurang bisa dipercaya, $0.21-0.40=$ agak bisa dipercaya, $0.41-0.60=$ cukup bisa dipercaya, $0.61-0.80=$ bisa dipercaya, dan $0.81-1.00=$ sangat bisa. Hasil uji reliabilitas masing-masing alat ukur dapat dilihat dalam tabel 2.

Tabel 2. Reliabilitas masing-masing alat ukur

\begin{tabular}{lc}
\hline \multirow{2}{*}{ Alat Ukur } & Alpha cronbach \\
$\begin{array}{l}\text { Budaya } \\
\text { organisasi }\end{array}$ & $\begin{array}{c}\text { Ujicoba }(\mathrm{N}=40) \\
\text { Dakwah }\end{array}$ \\
\hline
\end{tabular}

Dua alat ukur digunakan untuk mengumpulkan informasi mengenai variabel yang diteliti, yaitu skala budaya organisasi dan dakwah. Analisis data menggunakan Program SPSS for Windows versi 12 dengan teknik analisis regresi dan uji t.

\section{HASIL}

Hipotesis penelitian: ada pengaruh budaya organisasi terhadap dakwah kultural. Hipotesis itu diuji dengan teknik analisis regresi sederhana. Hasil analisis itu dapat dilihat pada tabel 2. 
Berdasar tabel 2 dapat dinyatakan budaya organisasi mempengaruhi dakwah kultural secara signifikan $(F(1,42)=39.189, \mathrm{p}<.05)$ dengan 48,3 persen sumbangan varian. Oleh itu hipotesis diterima. Namun demikian, sebanyak 51,7 persen varian lagi tidak dapat dihuraikan melalui model ini.

Tabel 2. Pengaruh budaya organisasi terhadap dakwah kultural

\begin{tabular}{lcccc} 
Sumber varian & df & $\mathrm{R}$ & $\mathrm{R}^{2}$ & $\mathrm{~F}$ \\
\hline $\begin{array}{l}\text { Budaya } \\
\text { organisasi }\end{array}$ & 1 & $\begin{array}{c}0.6 \\
95\end{array}$ & 0.483 & $\begin{array}{l}39.189 \\
*\end{array}$
\end{tabular}

Hasil persamaan regresi : $=.554$

$$
* \mathrm{p}<.05 \text {. }
$$

\section{Uji perbedaan demografi}

Terdapat dua variabel dalam penelitian ini, yaitu budaya organisasi dan dakwah. Kedua variabel itu akan dilihat perbedaannya dalam aspek demografi yang meliputi jenis kelamin dan jenis organisasi. Untuk menguji perbandangan aspek demografi itu ditentukan dengan melihat tingginya nilai min dengan teknik Uji t dan Anova 1 Jalur. Hasil analisis perbandingan budaya organisasi dan dakwah berdasar jenis kelamin dapat dilihat pada tabel 3 .

Tabel 3. Ringkasan perbedaan budaya organisasi dan dakwah berdasar jenis kelamin

\begin{tabular}{llcccc}
\hline \multicolumn{1}{c}{ Variabel } & JK & N & Min & Df & F \\
\hline $\begin{array}{l}\text { budaya } \\
\text { organisasi }\end{array}$ & Lk & 10 & 40,8000 & 42 &, 051 \\
dakwah & Lk & 10 & 38,0000 & & \\
& Pr & 34 & 17,6000 & 42 &, 110 \\
& & & & &
\end{tabular}

$* \mathrm{p}<.05$

Hasil analisis dapat dilihat pada tabel 3 . Tabel 3 menunjukkan hasil analisis statistik ujian t sebagai berikut:

1. Hasil menunjukkan min budaya organisasi diantara dai laki-laki dan dai perempuan adalah tidak secara signifikan $(\mathrm{F}(.42)=$ $.051 \mathrm{p}>.05)$.
2. Hasil menunjukkan min dakwah diantara dai laki-laki dan dai perempuan adalah tidak berbeda secara signifikan $(\mathrm{F}(.42)=$ $.110, \mathrm{p}>.05)$.

\section{PEMBAHASAN}

Secara umum, kajian mengenai pengaruh budaya organisasi terhadap persuasi belum ditemukan. Namun secara khusus, masing-masing varibel tersebut dapat ditemukan dalam kajian yang berbeda. Beberapa jurnal psikologi barat membahas budaya organisasi dengan dunia kerja dan produktivitas kerja. Kemudian secara independen persuasi yang termasuk dalam kajian pengaruh sosial (social influence) banyak dikaji melalui pendekatan eksperimen. Sama halnya dengan kajian psikologi, dalam kajian lepas psikologi Islami juga belum didaptkan mengenai hasil kajian tentang budaya organisasi dan aktivitas dakwah.

Namun sacara teoritik, pengaruh budaya organisasi terhadap aktivitas dakwah dapat terlihat dan pengaruhnya yang signifikan. Ada pernyataan dari beberapa tokoh yang menyatakan bahwa budaya organisasi dapat mempengaruhi anggotanya untuk melakukan aktivitas organisasi. Kuat tidaknya budaya organisasi yang dimiliki oleh anggotanya akan mempengaruhi kenerja organisasi dalam mencapai tujuan. Seperti penyataan dari Siagian (2004) bahwa budaya perusahaan yang kuat akan menumbuhkan tanggungjawab besar dalam diri individu, sehingga akan berupaya semaksimal mungkin untuk untuk /menampilkan kinerja yang paling memuaskan tanpa harus selalu didorong atau diawasi.

Pengaruh budaya organisasi terhadap perilaku anggotanya dapat terlihat dari fungsi budaya organsasi melalui aktivitas/program yang dijalankan, termasuk dalam kegiatan sosial dakwah Muhammadiyah. Seperti pernyataan tentang fungsi dari budaya orgsanisasi dari beberapa tokoh berikut:

a) Robbins (2005) menyatakan bahwa budaya organisasi mempermudah timbulnya pertumbuhan komitmen pada sesuatu yang lebih luas dari pada kepentingan diri sendiri. Kemudian pula budaya organisasi itu dapat 
meningkatkan kemantapan sistem sosial.

b) Sehubungan dengan fungsi komitmen tersebut, Siagian (2002) mengatakan bahwa para anggota organisasi akan bersedia membuat komitmen, termasuk memberikan pengorbanan sedemikian rupa, sehingga mereka akan ikhlas bekerja demi keberhasilan organisasi.

c) Sehubungan dengan segi sosial, Moeljono (2004) menyatakan bahwa budaya organisasi befungsi sebagai perekat sosial yang membantu mempersatukan organisasi itu dengan memberikan standar-standar yang tepat terhadap anggotanya untuk dapat bersikap dan melakukan tugas/aktivitas organisasi.

Untuk merangkum fungsi budaya organisasi di atas, dalam buku karangan Sholeh (2005) yang berjudul "manajemen dakwah Muhammadiyah" dapat disimpulkan bahwa budaya organisasi yang tinggi/baik itu mempunyai arti penting bagi oragnisasi, diataranya: para anggota memiliki kestabilan dan kepastian sikap, membantu meningkatkan produktivitas dan evektivitas organisasi, dan membuat perilaku anggota organisasi lebih konsisten dan memiliki komitmen yang tinggi.

Berdasar aspek deografi, penelitian ini menunjukkan tidak terdapat perbedaan budaya organisasi dan dakwah kultural berdasar jenis kelamin. Berdasar telaah dari berbagai literatur penelitian tentang aspek demografi menunjukkan hasil yang berbeda-beda antara satu dengan lainnya. Seperti Dewi (2006) menyatakan karakteristik biografikal seperti usia, jenis kelamin, status perkawinan, pendidikan, jumlah anggota keluarga dan masa kerja mempunyai pengaruh terhadap hasil organisasi. Lain halnya dengan hasil kajian Prabowo dan Johana (2007) menyatakan faktor karakteristik individu seperti usia, jenis kelaminan, status perkawinan dan masa kerja tidak mempengaruhi kegiatannya dalam pekerjaan.

Penulis menilai terjadinya perbedaan dan inkonsistensi tersebut disebabkan adanya faktor individu dan faktor lingkungan organisasi. Hal ini selaras dengan al-Qur`an surat al-Israa`ayat 84 dan al-Lail ayat 4 .

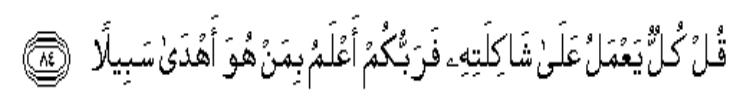

Terjemahannya: Katakanlah: "Tiap-tiap orang berbuat menurut keadaannya (tabiat dan pengaruh lngkungannya) masingmasing." Maka Tuhanmu lebih mengetahui siapa yang lebih benar jalannya (QS. alIsraa: 84).

Terjemahannya: Sesungguhnya (hasil) usaha kamu memang berbeda-beda (QS. al-Lail: 4).

Ayat tersebut bermakna bahwa setiap individu mempunyai kemampuan dasar yang unik dan berbeda dengan individu lainnya. Perbedaan itu meliputi aspek bio, psiko, sosial dan spiritual. Aspek inilah yang membuat setiap individu berbeda dengan orang lain, termasuk kegiatannya dalam organisasi.

\section{KESIMPULAN}

Kesimpulan ini menjawab masalah dan tujuan penelitian yang dikaitkan dengan hasil penelitian dan pembahasan yang telah dihurai sebelumnya. Oleh itu dapat dinyatakan kesimpulan penelitian sebagai berikut:

1. Terdapat pengaruh budaya organisasi terhadap dakwah kultural secara signifikan, dengan 48,3 persen sumbangan varian. Namun demikian, sebanyak 51,7 persen varian lagi tidak dapat dihuraikan melalui model ini.

2. Dari aspek demografi, hasil penelitian ini menunjukkan tidak terdapat perbedaan budaya organisasi dan dakwah kultural berdasar jenis kelamin.

Implikasi penelitian ini diarahkan pada sumbangan terhadap pembangunan teoritikal dan pengembangan organisasi yang bersifat praktis. Secara teoritikal, penelitian ini memberikan sumbangan pada perluasan wawasan dalam penelitian psikologi organisasi mengenai konsep budaya organisasi. Selain itu, secara khusus penelitian ini juga memperluas wawasan penelitian Psikologi Islami mengenai konsep aktivitas dakwah yang diarahkan mendukung psikologi pribumi (Indigenous 
Psychology).Secara praktis, penelitian ini memberi sumbangan strategik organisasi sosial keagamaan, khususnya Muhammadiyah untuk memperrhatikan SDM dalam rangka menanamkan nilai-nilai budaya organisasi kepada anggotanya.

\section{DAFTAR RUJUKAN}

\section{Al-Qur`an}

Azwar, Saefuddin. 2003. Metode penelitian. Yogyakarta: Pustaka Pelajar.

Azwar, Saefuddin. 2009. Penyusunan skala psikologi. Yogyakarta: Pustaka Pelajar.

Dewi, Anak A.S.K. 2006. Analisis beberapa faktor yang mempengaruhi partisipasi karyawan (suatu kajian teori). Buletin Studi Ekonomi vol. 1 nomor 1hal. 10-18.

George, J.M. dan Jones, G.R. 1996. Understanding an Managing Organizational Behavior. Addision Wesley Publishing Company.

Langdon, A. dan Marshall, P. 1998. Organisational Behavoir. Addision Wesley Publishing Company.

Mansyur, Ahmad Yasser. 2007. Kumpulan materi dan tema-tema Psikologi bersumber dari Al-Qur`an. Makassar: Fakultas Psikologi UNM.

Moeljono, D. 2004. Budaya Korporat dan Keunggulan Korporasi. Jakarta: Elex Media Komputindo.

Munawir, A.W. 2002. Al-Munawwir: Kamus Arab - Indonesia terlengkap. Surabaya: Pustaka Progressif.

Nashir, Haedar. 2007. Meneguhkan Ideologi Gerakan Muhammadiyah. Malang: UPT Penerbitan Universitas Muhammadiyah Malang.

Newcomb, T.M., Turner, R.H., dan Converse, P.E. 1978. Psikologi Sosial. Alih Bahasa: Tim Psikologi Universitas Indonesia. Bandung: Diponegoro.

Pimpinan Pusat Muhammadiyah. 2005. Keputusan Muktamar Muhammadiyah ke45 tahun 2005 di Kota Malang tentang pernyataan pikiran Muhammadiyah jelang satu abad (Zhawãhir al-Afkãr alMuhammadiyyah 'Abra Qarn min alZamãn).

Pimpinan Pusat Muhammadiyah. 1424 H / 2003 M. Dakwah Kultural Muhammadiyah, Diajukan dalam Sidang Tanwir Muhammadiyah di Makassar Tanggal 26-29 Juni 2003.

Prabowo, Rinto \& Johana E. Prawitasari. 2007. Kinerja pegawai kantor Dinas Kesehatan Kota Tanjungbalai Propinsi Sumatera Utara ditinjau dari faktor karakteristik individu dan lingkungan kerja. Working Paper Series No. 15, First Draft.

Robbins, S.P. 2005. Organization Behavior, Elevent Edition. Pearson - Prentice Hall.

Sears, D.O., Freedman, J.L., dan Peplau, L.A. 1985. Social Psychology, Fifth Edition. Prentice Hall, Inc.

Sholeh, R.A. 2005. Manajemen Dakwah Muhamamdiyah. Yogyakarta: Suara Muhammadiyah.

Siagian, S.P. 2002. Kiat Meningkatkan Kreativitas Kerja. Jakarta: Rineka Cipta.

Weiss, J.W. 2001. Organizational Behavior an Change Managing Diversity, Cros Culture Dynamic and Etnics. South - Westren: College Publishing.

Wikipedia Indonesia, ensiklopedia bebas berbahasa Indonesia. http://id. wikipedia.org. Diambil pada tanggal 15 Juli 20014. 